\title{
The Impact of the Entrepreneurial Learning Environment on Students' Entrepreneurial Intention in Yusuf Maitama Sule University, Kano
}

\author{
Shamsu Lawan Abubakars*, Mahabub Musa Garba \\ Department of Business Administration, Faculty of Social and Management Sciences, Yusuf Maitama Sule University, Kano, \\ Nigeria \\ Email: ^shamsulawan46@gmail.com,mahbub@nwu.edu.ng
}

How to cite this paper: Abubakars, S. L., \& Garba, M. M. (2021). The Impact of the Entrepreneurial Learning Environment on Students' Entrepreneurial Intention in Yusuf Maitama Sule University, Kano. Open Journal of Social Sciences, 9, 458-469.

https://doi.org/10.4236/jss.2021.912029

Received: September 6, 2021

Accepted: December 28, 2021

Published: December 31, 2021

Copyright $\odot 2021$ by author(s) and Scientific Research Publishing Inc. This work is licensed under the Creative Commons Attribution International License (CC BY 4.0).

http://creativecommons.org/licenses/by/4.0/

\begin{abstract}
The aim of this research is to examine the influence of entrepreneurial learning environment on entrepreneurial intention among undergraduate students in Yusuf Maitama Sule University, Kano. To achieve that, cross-sectional survey design was used where a questionnaire was employed as the technique for data collection. A sample of 334 respondents was used in the study. Findings show that the dimensions of the entrepreneurial learning environment (the physical and the mental) are positively and significantly associated with students' entrepreneurial intentions. Thus, among the recommendations of the study, the management of the university saddled with the responsibility of teaching entrepreneurship courses should find a way of integrating people with enterprise experience in teaching entrepreneurship.
\end{abstract}

\section{Keywords}

Mental Environment, Physical Environment, Entrepreneurial Intention

\section{Introduction}

Entrepreneurial intention is one of the cardinal objectives entrepreneurship education is set to achieve. With entrepreneurship intention, the possibility of entrepreneurship to flourish is very high. However, with entrepreneurship, many of the world challenges can be addressed, such as poverty, unemployment and insecurity of jobs. That is why, according to many researchers and policy makers, to have sustainable development there is a need for entrepreneurship in any 
given society and among the facilitators of entrepreneurship is entrepreneurial intention.

Entrepreneurship education has been contributing in the area of students' entrepreneurial intention even though in most of the researches entrepreneurship education does not positively influence students' entrepreneurial intention or has a very small positive effect on students' entrepreneurial intention. Previous studies have shown that many factors are responsible for entrepreneurial inclination, interest and even intention for venture creation. The increasing interest and desire in entrepreneurial research have been aligned to the impact of entrepreneurship and the role it plays in economic development through innovation, new inventions, and job opportunities, a revival of an inactive economy and other aspects of the economy. Unemployment among youth especially graduates has, therefore, become a hindrance to the economic growth and development for some countries and the citizenry as well, hence the need to investigate in an attempt to find out the impact of the entrepreneurial learning environment on students' entrepreneurial intention.

The theory of planned behaviour and theory of entrepreneurial event are of the view that attitude, perceived behavioural control, social norms, perceived desirability, perceived feasibility and propensity to act are the determinants of individual intention and many researchers have used the models to examine their effects on students' entrepreneurial intention. According to Garba, Kabir and Nalado (2014), both perceived desirability and perceived feasibility are not the determinants of entrepreneurial intention even though students have undertaken entrepreneurship education. Similarly, in a study Neneh (2014) classified the antecedents of entrepreneurial intention into pull, push, endogenous and exogenous factors even though entrepreneurship education was used as a demographic factor in the study. It showed that what triggers entrepreneurial intention majorly are push factors, such as poverty, unemployment and job security. The study further affirms that the major factor that inhibits students from choosing entrepreneurship as a career option is finance.

Other studies have examined the influence of culture, family background, gender, entrepreneurship education, motivation, environmental factors, educational levels, etcetera on students' entrepreneurial intention (Lee, Chang, \& Lim, 2005; Ismail, 2015; Siyanbola, Afolabi, Jesuleye, Egbetokun, Dada, Aderemi, Sanni, \& Razak, 2009; Lucky \& Auwalu, 2015). Most of the studies have reiterated the importance of entrepreneurship education in triggering entrepreneurial interest and intention but the impact is either reported to be negative or positively insignificant. In the study conducted by Oosterbeek, Praag and IJsselstein (2010), the entrepreneurship education programme is negatively related to entrepreneurial intention and has no significant impact on entrepreneurial skills. In the recent study conducted by Mahabub and Abubakar (2019), the impact played by the entrepreneurial learning environment is meagre toward influencing entrepreneurial intention. Ahmad, Abu Kar and Ahmad (2018) are of the view that the 
reason why entrepreneurship education does not achieve the desire result is because of teaching methods. However, according to Lucky and Auwalu (2015), environmental factors, such as environmental supports and influence, are not the real determinants of entrepreneurial intention. Though in the study conducted by Mahabub and Abubakar (2019) entrepreneurial learning environment has been considered as an independent variable, which has no proxies and has been considered as a unidimensional variable, in their study. In the report by OECD (2015), the constituting elements that make-up entrepreneurial learning environment are basically classified into two vis-à-vis mental and physical environments.

In order to get more insight on the impact of entrepreneurship education specifically, the effects of the entrepreneurial learning environment and on the fact that the major reasons that make students go into entrepreneurship are largely revolved around push factors, such as poverty, unemployment and insecurities of jobs, as shown in the literature, however, this study is aimed to examine the influence of physical and mental learning environment toward influencing entrepreneurial intention.

\section{Theoretical Framework and Literature Review}

Entrepreneurial intention with entrepreneurship education, entrepreneurial intention can be sustained to about prosperity in entrepreneurship. Entrepreneurial attitude, skills and intention can truly trigger once there is the strong presence of entrepreneurship education. It is considered as education for all because of its capacity to touch every nook and cranny of society from students to socially marginalised groups (Volkman, Wilson, Mariotti, \& Rabuzzi, 2009). Therefore, with the influence of entrepreneurship education more enterprising individuals can be produced and entrepreneurial intention sustained (Cho, 1998). In the previous studies the antecedents to entrepreneurial intention were analysed and categorised into different components. Some were considered as theoretical factors, such as antecedents to the theory of planned behaviour and the theory of entrepreneurial events. Others are terms as traits factors, such as the influence of individual characteristics-the need for achievement, internal locus of control, and creativity, while some of the factors were considered either push or pull factors, such as the desire for independence, financial autonomy, poverty and unemployment. Others have classified the factors into demographics, such as the influence of culture, gender, entrepreneurial experience, entrepreneurship education, etcetera. Lastly, are environmental factors, such as support from educational institutions, financial support, favourable business climate, the right calibre of human resources, the availability of raw-materials, the role of government and other related factors. Thus, the aim of this aspect is to review the literature on the factors that influence entrepreneurial intention and find gaps that are not yet addressed by previous studies.

Entrepreneurial intention is one of the major impetuses that can trigger en- 
trepreneurial action. However, entrepreneurial intention is about getting the interest and conviction of starting a venture; the venture can be a social or a business venture (Ismail, 2015). In the field of entrepreneurship, the dominant theories linked to entrepreneurial intention are the theory of entrepreneurial event, which is of the view that the intention to act on a given behaviour largely depends on perceived desirability, perceived feasibility and the propensity to act, and theory of planned behaviour which asserts that the intention to perform a given behaviour or action depends on attitude, perceived behavioural control and social norms. In these theories, intention, including entrepreneurial intention, can be formed within factors that are within individual domain as well as external factors. In the study conducted by Garba et al. (2014), perceived desirability, which is synonymous to attitude and perceived feasibility, which is akin to behavioural control, are not the determinants of entrepreneurial intention. In their research, both perceived desirability and perceived feasibility have no significant relationship with entrepreneurial intention even though students have taken the entrepreneurship education course. Though in the study by Lee et al. (2005) entrepreneurship education is not the strongest factor that influences entrepreneurial intention, most especially among students in the USA, rather entrepreneurial culture is the major determinant of entrepreneurial intention among students there even though the study has shown that entrepreneurship education facilitated entrepreneurial intention in selected Korean universities.

Oosterbeek et al. (2010) examined an entrepreneurship education programme to figure out its impact on students' entrepreneurial skills and intention. The study concluded that the programme, was not significantly related to entrepreneurial skills and also was negatively related to entrepreneurial intention. However, Neneh (2014) holistically examined the factors that influence students' entrepreneurial intention, which he classified as push, pull, exogenous and endogenous. In this research, push factors were considered as the most significant factors that trigger students' interest toward entrepreneurship. The factors include poverty, unemployment and job security. The study also shows that factors, such as inadequate fund were among the inhibitors of entrepreneurial intention. The influence of entrepreneurship education toward entrepreneurial intention is meagre. Other studies, such as Ismail (2015), examined the effects of individual motivation on students' entrepreneurial intention. The study concluded that financial autonomy, becoming my own boss and a host of related factors, are what motivate newly enrolled university to choose entrepreneurship as a carrier option. But the study further affirmed that once a student can have access to finance, they cannot only have entrepreneurial interest but also engage into entrepreneurial actions. Siyanbola et al. (2009) embarked on the research to examine the determinants of the entrepreneurial propensity of Nigerian undergraduates. In this research, the binary method was employed in requesting responses from respondents. The study shows that Nigerian undergraduate students have high entrepreneurial interest and at the same time low entrepreneurial action. The paper shows that academic performance has no correlation 
with students' interest to become entrepreneurs. The paper further revealed that entrepreneurship education plays a significant role in influencing student's role toward entrepreneurship. However, that does not translate into entrepreneurial action.

In the study conducted by Misoska, Dimitrova and Mrsik (2016), they asserted that one of the ways to achieve greater interest in entrepreneurial activities is through entrepreneurship education at the levels of university. This study used theory of planned behaviour to see how it influenced students' entrepreneurial intention. From the results of the study, subjective norms positively influence attitude and behavioural control. The study also shows that educational experiences that develop knowledge about entrepreneurship have a statistically significant influence on subjective norms, attitudes towards behaviour and perceived behavioural control. The study further shows that educational experience is positively related to entrepreneurial intention but in a very minimal level. The paper also shows that knowledge about a support system makes a more positive impact in influencing entrepreneurial intention among students in Macedomia. The perception of students about the business climate positively influences their entrepreneurial intention. And from this study, educational experiences and knowledge about support system as well as the business climate positively influence entrepreneurial intentions.

From most of the literature reviewed, it is shown that the impact played by the entrepreneurship education programme is a little bit meagre in the area of influencing entrepreneurial intention. This raises an important question that the entrepreneurial learning environment needs to be investigated so as to understand more on the impact of entrepreneurship education toward influencing entrepreneurial intention. Thus, the main purpose of this study is to examine the impact of the physical and mental teaching environment toward influencing entrepreneurial intention. In order to achieve the objectives of the study a conceptual framework was developed as indicated in Figure 1.

\section{Methodology}

The target population was final year undergraduate students across the University irrespective of their course of study, who learned entrepreneurship education in their third and fourth year. Conducting a survey research on final year students as target population is applicable to test entrepreneurial intention. This study specifically used the cross-sectional survey design to examine the impact of the entrepreneurial learning environment (the metal and the physical) toward the entrepreneurial intention of the final year students of Yusuf Maitama Sule University, Kano, Nigeria 2019-2020 academic session. The population of the study comprised 2500 final year students ranging from regular Level 400 to Spill over 2. The sample of the study was drawn based on Krejcie and Morgan (1970). 334 students formed the sample size. Convenient sampling was used as the sampling technique for the study whereby each of the respondents was selected based on his/her personal interest. Therefore, questionnaires were distributed 


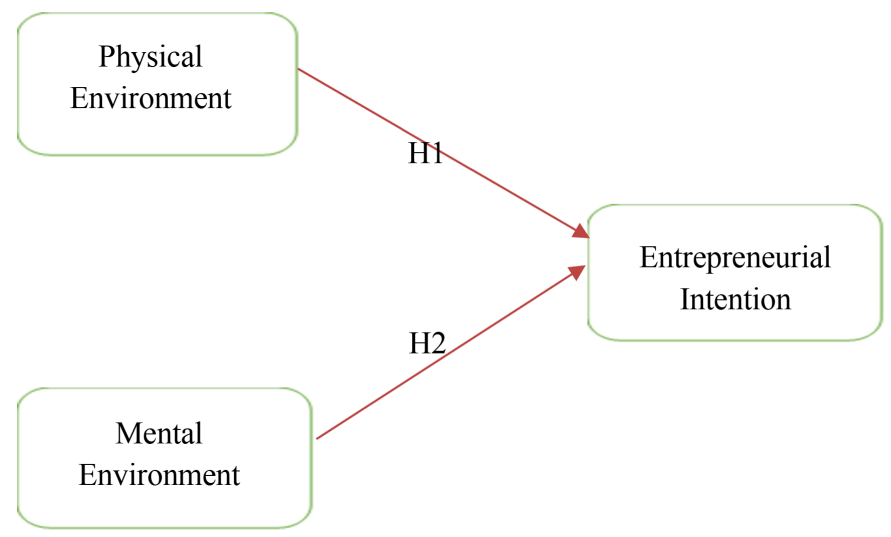

Figure 1. Conceptual framework.

for data collection. Students were brief about the guidelines on how to respond to the questionnaire as depicted on the first page of the questionnaire. Students' response confidentiality was assured to enable them give out appropriate answers to achieve the research objective. Moreover, out of 334 questionnaire distributed, only 266 (77.3\%) were retrieved which is of the respondents. After preliminary analyses of the retrieved questionnaires and data screening, only 246 (73.7\%) were valid and used for analyses.

\subsection{Measures}

The variables of this study were adapted from previous studies and measured on a 5 -point measurement scale, which ranges from $1=$ strongly disagree to $5=$ strongly agree. Essentially, entrepreneurial intention and the dimensions of the entrepreneurial learning environment were measured based on the work of Mahabub and Shamsu (2019). Students' entrepreneurial intention was measured using the entrepreneurial learning environment, i.e. Entrepreneurial intention (5 items) which are: I am now zealous to start a business; I am ready to do anything to be an entrepreneur; I am determined to create a business in the future, now my professional goal is to be an entrepreneur and I have a very low intention to start a business. The learning and physical environment (6 items), includes My university have a start-up lab where a student can learn about the practice of entrepreneurship; My university embarks on industrial visits in order for students to learn about entrepreneurship; My school employs the services of an external resource person to teach us about entrepreneurship; My university has a workshop where students learn about the practice of entrepreneurship; My university provides us with internet links, which can enable one to learn about the practice of entrepreneurship and My university's physical facilities have little influence in my intention to start a business in the future. Mental environment (5 items) includes: The assignment we are given encourages one to become an entrepreneur; The method used by our teachers involved more of practical rather than the theory of entrepreneurship; My university gives emphasis on giving projects to students that really promote the practice of entrepreneurship; My university en- 
courages the development of a Business Plan in teaching entrepreneurship and My university heavily relies on class lecture and examination in teaching entrepreneurship.

\subsection{Method of Data Analysis}

The data of this research is analyzed using descriptive and inferential statistics. In the conduct of the analysis, the statistical package of the social sciences (SPSS) version 23 and partial least square structural equation modelling (PLS-SEM) version 3 were used. However, information regarding to the biodata of the respondents were analyzed using descriptive method while analysis for the variables of the study were analyzed using inferential statistics.

\section{Results}

\subsection{Demographic Profile of the Respondents}

The respondents profile shows that $138(56.1 \%)$ are male and $108(43.9 \%)$ are female. On age bracket, $219(89 \%)$ are between 30 years and below while, 26 (10.6\%) are between 31 - 40 years and those aged $41-50$ are just 1 (0.4\%). In marital status, $172(69.9 \%)$ are single and $72(29.3 \%)$ married. Meanwhile, 1 is separated $(0.4 \%)$ and lastly one is also $(0.4 \%)$ widowed. Finally, the respondents belong to different faculties in the university. It has been established from the data collected that 79 (32.1\%) from Faculty of Social and Management Sciences, 59 (24.0\%) are from Faculty of Education, 55 (22.4) are from Faculty of Humanities, 31 (12.6\%) are from Faculty of Science and, finally, 22 (8.9\%) from Faculty of basic Medical Sciences. Thus, the demographic information indicated that majority are male, aged 30 years and below and single in terms of marital status.

\subsection{Preliminary Analysis}

According to Hair, Money, Samouel and Page (2007) data screening is a basic requirement and essential for multivariate analysis. This is so pertinent because it allows researchers to figure any tendency for violations to basic multivariate analysis assumptions. Following the input and coding of the data preliminary analyses were conducted in relation to missing data values, the assessment of potential outliers and the test of normality and assessment of multicollinearity (Tabachnick \& Fidell, 2007; Hair et al., 2010). From the results of data editing and screening some items have the problem of missing value, which were either corrected or completely deleted from the data set. Based on Hair et al. (2010), any case of missing value should be erased once the sample size adequacy has been achieved. Following the satisfaction of normality in the data set, the data were further used for multivariate analysis.

All the constructs of the study achieved the acceptable level of internal consistency composite reliability values of 0.70 (Hair et al., 2011). This has been depicted in Table 1 below. Similarly, convergent validity was also attained with each of the average variance extracted (AVE) values of the constructs presenting 
a value of at least 0.50 (Hair et al., 2010), as depicted in Table 1 below.

The discriminant validity was also confirmed using the Fornell and Larcker (1981) criteria were the square root of AVE for each construct proves to be greater than values within the same line of the correlation matrix as depicted in Table 2 below.

From Table 1 above, all the constructs in this study attained a satisfactory CR value of $\geq 0.70$ and AVE value of at least 0.50 (Hair et al., 2010). On the same measurement model, the Fornell and Larcker (1981) discriminant validity benchmark was also applied to examine the discriminant validity of the constructs. In discriminant validity, the square root of AVE values for each construct proved to be greater than the values within the same line of the correlation matrix as can be seen in Table 2 below.

Convergent validity was also attained with each of the average variance extracted (AVE) values of the constructs presenting a value of at least 0.50 (Hair et al., 2010), as depicted in Table 1 below.

The discriminant validity was also confirmed using the Fornell and Larcker (1981) criteria were the square root of AVE for each construct proves to be greater than values within the same line of the correlation matrix as depicted in Table 2 below.

\subsection{Path Analysis and Hypothesis Testing}

The main purpose of the study was to examine the influence of the physical and mental teaching environment toward influencing entrepreneurial intention. Table 3 represents the results of the path analysis conducted. From the table, the result of the analysis accepted $\mathrm{H} 1$, which represents a positive and significant association with a beta value of 0.167 and a $p$-value of 0.011 . H2 was also

Table 1. Reliability coefficients and AVE.

\begin{tabular}{ccc}
\hline Variables & Composite Reliability & AVE \\
\hline EI & 0.775 & 0.538 \\
ME & 0.829 & 0.55 \\
PE & 0.829 & 0.618 \\
\hline
\end{tabular}

Table 2. Correlations of constructs and AVE square roots.

\begin{tabular}{ccccc}
\hline S/No. & Variables & 1 & 2 & 3 \\
\hline 1 & Entrepreneurial Intention & 0.734 & & \\
2 & Mental Environment & 0.247 & $\mathbf{0 . 7 4 2}$ & \\
& & 0.252 & 0.452 & \\
3 & Physical Environment & & & $\mathbf{0 . 7 8 6}$ \\
\hline
\end{tabular}

Note: Italic (originally bold) figures represents AVE square root. 
Table 3. Path analysis any hypothesis testing.

\begin{tabular}{ccccccc}
\hline Effects & Hypothesis & Relationship & Beta & $\boldsymbol{t}$-stat & $\boldsymbol{p}$-value & Results \\
\hline Direct & H1 & MEàEI & 0.167 & 2.279 & 0.011 & Accepted \\
Direct & H2 & PEàEI & 0.177 & 2.647 & 0.004 & Accepted \\
\hline
\end{tabular}

accepted and indicates a significant positive relationship with a beta value of 0.177 and a $p$-value of 0.004 respectively.

Although both the mental and the physical environments have shown a positive significant relationship, the relationship is stronger with the physical environment compared to the mental. The components of the physical environment, as such involving persons with practical knowledge in teaching entrepreneurship and providing start-up labs, have more impact on students' entrepreneurial intention than mere using passive methods of learning in training them on how to become entrepreneurs.

\section{Discussion}

The primary motive for this research is to examine the influence of entrepreneurial learning environment on the entrepreneurial intention of graduating students of Yusuf Maitama Sule University, Kano. The result shows that the dimensions of the entrepreneurial learning environment, such as physical environment and mental environments have a positive and significant relationship with students' entrepreneurial intention. In the context of this study, if the entrepreneurial environment can be improved, it can have a significant influence in producing more entrepreneurs. This is because the better the method of teaching entrepreneurship the more likely that more enterprising individuals can be produced.

Therefore, this study has produced that entrepreneurship education can in a long way produce more enterprising individuals especially when there is the right combination of teaching methods. This research is an indication that if students enjoy the best method of teaching, the propensity to become entrepreneurs' increases. This negate the findings of Neneh (2014), which found that push factors have more influence toward making students become entrepreneurs. However, in the study conducted by Mahabub and Abubakar (2019), there is little influence of the learning environment on entrepreneurial intention. This study shows the negative, that is, a better entrepreneurial learning environment has a significant influence on students' entrepreneurial intention. Furthermore, Garba et al. (2014) established that perceived desirability and perceived feasibility are not the determinants of students' entrepreneurial intention but with a better learning environment students' feasibility and desirability toward entrepreneurship may increase. Therefore, more needs to be done on the influence of entrepreneurial learning environment on students' perceived desirability and perceived feasibility.

Other studies examined the influence of culture, family background, gender, 
entrepreneurship education, motivation, environmental factors, educational levels, etcetera on students' entrepreneurial intention (Lee, Chang, \& Lim, 2005; Ismail, 2015; Siyanbola, Afolabi, Jesuleye, Egbetokun, Dada, Aderemi, Sanni, \& Razak, 2009; Lucky \& Auwalu, 2015). Most of the studies reiterated the importance of entrepreneurship education in triggering entrepreneurial interest and intention but the impact is either reported to be negative or positively insignificant. Therefore, from this study why the impact is either negative or insignificant is because of teaching methods. Once there are better methods of teaching entrepreneurship, more flourishing enterprising can be seen.

From the discussion, one can figure out that to achieve good students' entrepreneurial intention, there is the need for a better entrepreneurial learning environment. However, relying on a passive method of teaching entrepreneurship has a limited impact in making students become entrepreneurs. But devising methods that involve more practice can be the most effective factor in producing better student entrepreneurs.

\section{Conclusion and Recommendations}

This study focused on the influence of the entrepreneurial learning environment on the entrepreneurial intention of undergraduate students in Yusuf Miatama Sule University, Kano. It identified two major dimensions of the entrepreneurial learning environment vis-à-vis physical environment and mental environments. From the study, each of the dimensions of the entrepreneurial learning environment has a positive and significant influence toward students' entrepreneurial intention. The study affirmed that physical and mental environments have a positive and significant influence on students' entrepreneurial intention, but physical environment has more impact in influencing their' entrepreneurial intention. Therefore, based on the findings, the following recommendations were given:

1) The management of the university saddled with the responsibility of teaching entrepreneurship courses should find a way of integrating people with enterprise experience in teaching entrepreneurship.

2) Establish business incubation centres where students can explore more about the practice of entrepreneurship.

3) More hands on than hands off in teaching entrepreneurship.

4) The management of the university should establish a foundation that can assist students in getting financial support, especially those with workable and viable business ideas.

5) Lastly, the study recommended that more studies need to be conducted on the influence of the entrepreneurial learning environment on students' perceived desirability and perceived feasibility toward entrepreneurship.

\section{Acknowledgements}

The authors would like to acknowledge the contributions of Dr. Mahmoud Ahmad Mahmoud and Professor Aliyu Kamal. 


\section{Funding}

This project was funded by Tertiary Education Trust Fund (TETFUND).

\section{Conflicts of Interest}

The authors declare no conflicts of interest regarding the publication of this paper.

\section{References}

Ahmad, S. Z., Abu Bakar, A., \& Ahmad, N. (2018). An Evaluation of Teaching Methods of Entrepreneurship in Hospitality and Tourism Programs. The International Journal of Management Education, 16, 14-25. https://doi.org/10.1016/j.ijme.2017.11.002

Cho, B. (1998). Study of the Effective Entrepreneurship Education Method and Its Process. Business Education Research, 2, 27-47.

Fornell, C., \& Larcker, D. F. (1981). Evaluating Structural Equation Models with Unobservable Variables and Measurement Error. Journal of Marketing Research, 18, 382-388. https://doi.org/10.1177/002224378101800313

Garba, S. A., Kabir, S., \& Nalado, A. M. (2014). An Assessment of Students' Entrepreneurial Intentions in Tertiary Institution: A Case of Kano State Polytechnic, Nigeria. International Journal of Asian Social Science, 2, 434-443.

Hair Jr., J. F., Black, J. W., Babin, B. J., \& Anderson, E. R. (2010). Multivariate Data Analysis (7th ed.). Pearson Education.

Hair, J. F., Hult, G. T. M., Ringle, C. M., \& Sarstedt, M. (2011). A Primer on Partial Least Squares Structural Equation Modeling (PLS-SEM). Sage Publications.

Hair, J. F., Money, A. H., Samouel, P., \& Page, M. (2007). Research Method for Business. John Wiley and Sons.

Ismail, A. (2015). The Entrepreneurial Attitude and Intentions of Newly Enrolled University Students-Issues and Policy Implication. Journal of Research in Business, Economics and Management, 4, 426-436.

Krejcie, R. V., \& Morgan, D. W. (1970). Determining Sample Size for Research Activities. Educational and Psychological Measurement, 30, 607-610. https://doi.org/10.1177/001316447003000308

Lee, S. M., Chang, D., \& Lim, S. B. (2005). Impact of Entrepreneurship Education: A Comparative Study of the US and Korea. The International Entrepreneurship and Management Journal, 1, 27-43. https://doi.org/10.1007/s11365-005-6674-2

Lucky, E. O., \& Auwalu, N. I. (2015). Environmental Factors and Entrepreneurial Intention among Nigerian Students in UUM. Sains Humanika, 5, 87-93.

Mahabub, M. G., \& Abubakar, S. L. (2019). The Influence of Entrepreneurial Learning Environment and Intrinsic Learners' Needs on Entrepreneurship Education. Open Journal of Business and Management, 7, 1244-1261. https://doi.org/10.4236/ojbm.2019.73087

Misoska, A. T., Dimitrova, M., \& Mrsik, J. (2016). Drivers of Entrepreneurial Intentions among Business Students in Macedonia. Economic Research, 29, 1062-1074. https://doi.org/10.1080/1331677X.2016.1211956

Neneh, B. N. (2014). An Assessment of Entrepreneurial Intention among University Students in Cameroon. Mediterranean Journal of Social Sciences, 5, 544-552. https://doi.org/10.5901/mjss.2014.v5n20p542 
OECD (Organisation for Economic Co-Operation and Development) (2015). Entrepreneurial Learning Environments and a Changed Role for Teachers. Thematic Paper on Entrepreneurial Schools Part 2, Organisation for Economic Co-operation and Development.

Oosterbeek, H., Van Praag, M., \& Ijsselstein, A. (2010). The Impact of Entrepreneurship Education on Entrepreneurship Skills and Motivation. European Economic Review, 54, 442-454. https://doi.org/10.1016/j.euroecorev.2009.08.002

Siyanbola, W. O., Afolabi, O. O., Jesuleye, O. A., Egbetokun, A. A., Dada, A. D., Aderemi, H. O., Sanni, M., \& Razak, M. (2009). Determinants of Entrepreneurial Propensity of Nigerian Undergraduates: An Empirical Assessment. Inderscience Publishers, National Centre for Technology Management.

Tabachnick, B. G., \& Fidell, L. S. (2007). Using Multivariate Statistics (5th ed.). Pearson Education.

Volkman, C., Wilson, K., Marlotti, S., \& Rabuzzi, D. (2009). Educating the Next Wave of Entrepreneurs: Unlocking Entrepreneurial Capabilities to Meet the Global Challenges of the 21st Century. World Economic Forum: A Report of the Global Education Initiative. 